\title{
EL LENGUAJE IRRACIONAL DEL CÍCLOPE: RETÓRICA Y POLÍTICA EN ESTE MITO
}

\author{
Gilberto Castro Delgado
}

\section{(c) ${ }_{\mathrm{EY}} \mathrm{NO} \mathrm{ND}_{\mathrm{ND}}$}

Doi: https://doi.org/10.15517/rfl.v46iEspecial.41506

URL: https://revistas.ucr.ac.cr/index.php/filyling/index 



\title{
EL LENGUAJE IRRACIONAL DEL CÍCLOPE: RETÓRICA Y POLÍTICA EN ESTE MITO
}

\author{
NON-RATIONAL SPEECH OF THE CYCLOPS: RHETORICAL \\ AND POLITICAL ASPECTS WITHIN THIS MYTH
}

\section{Gilberto Castro Delgado}

\begin{abstract}
RESUMEN
En el siguiente artículo se trata el tema del lenguaje del cíclope Polifemo como una proyección de un estado de comunicación social con rasgos de elementos apolíticos. Quiere decir esto que el cíclope, aunque se comunicaba, carecía de un discurso digno de una sociedad avanzada en el contenido de las leyes y de las destrezas discursivas propias del hombre social, tal como se define desde los lineamientos culturales de la sociedad occidental a partir de las ideas filosóficas de Platón y de Aristóteles. En este sentido, Polifemo constituye una antítesis con respecto a Odiseo.

Palabras clave: política; retórica; mito; héroe; areté.
\end{abstract}

\begin{abstract}
The aim of this paper is the study of the manner how the Cyclops Polyphemus spoke and then we could obtain a kind of social communicative stuff within apolitical statements. This is, although the Cyclops had a language trough out he communicates, he did not possess a notable speech proper of a modern society with their particular lows and the skills of a productive speech which belong to the men who lives social conditions as a common political unity, such as the philosophical ideas from Plato and Aristotle. So this is, Polyphemus and Odysseus are in an antithetical position.

Keywords: politics; rhetoric; myth; hero; arete.
\end{abstract}

\section{Introducción}

Homero, en el libro noveno de la Odisea, narra las aventuras que pasó Odiseo con sus compañeros en la isla de los cíclopes, y del relato se sustrae la forma de vida de estos seres, casi prehistórica, comparada con la vida política de Odiseo.

El relato de los cíclopes es un indicador de que los seres humanos están en referencia continua con otros mundos que contrastan con el suyo propio. El hecho de nombrar otros mundos y de actuar con ellos constituye lo que Choza y Choza (1996) denominan el universo de la cultura. Este hecho expresa que el hombre encuentra modos de vida muy diferentes a los suyos, incluso en cuanto al uso del lenguaje.

Lic. Gilberto Castro Delgado. Profesor de la Escuela de Filología, Lingüística y Literatura. Universidad de Costa Rica. Costa Rica. Correo electrónico: gilbertico11@yahoo.es

Recepción: 20- 06- 19

Aceptación: 20- 11- 19 
Sin embargo, no podría afirmarse que estos seres míticos hayan carecido de ciertos indicios de cultura, ya que, según el relato homérico, lograban comunicarse entre sí y con los forasteros con un lenguaje apenas expresivo, como cuando comunica a Odiseo su intención de devorar a los extranjeros en su cueva, o cuando agradece por el buen vino, o cuando alerta a los otros cíclopes de su desventura.

Además de Homero, se tienen referencias acerca de los cíclopes, en especial del personaje Polifemo, en otros autores posteriores entre los que destacan Teócrito con sus idilios, Eurípides con su drama satírico El Cíclope, Ovidio con sus elegías y más recientemente Góngora. En estos autores se reconoce un tipo de habla en los cíclopes que es elegante y expresivamente poética, pero se trata de autores que son verdaderos poetas, por lo que es fácil comprender que su lenguaje resulta poético e incluso elocuente.

Sin embargo, el lenguaje del cíclope Polifemo, a pesar de cierta elocuencia, como ocurre recursivamente en muchos pasajes de la obra homérica (Glauco con Diomedes, Héctor con Aquiles, Odiseo en las distintas cortes, etc.), no alcanza el nivel del lenguaje dialéctico, es decir, del uso expresivo de la lengua con arte retórica y razonamiento para defender con buenos argumentos y con persuasión las convicciones propias contra las ideas del contrario, como ha prevalecido en la civilización occidental gracias a las teorías retóricas de los pensadores antiguos, como Aristóteles. En consecuencia, se puede afirmar que el enfrentamiento entre Polifemo y Odiseo constituye una antítesis en el discurso retórico y, por lo tanto, se puede establecer que el análisis del discurso entre estos dos personajes tiene como fin determinar las diferencias entre dos sociedades humanas en las que lo político juega un papel primordial según la preceptiva retórica de los tratados que han llegado a nuestros días, como lo afirma López Eire (2006):

La «retoricidad» del lenguaje, la naturaleza retórica del lenguaje, no es una moderna innovación conceptual de última hora, pues la idea de que el lenguaje es retórico es antigua y de algún modo la intuyeron ya los antiguos griegos, que luego la formularon explícitamente. El lenguaje es retórico porque es, al mismo tiempo politico-social y simbólico (p. 23).

Así, se destaca el lenguaje del hombre dentro del dominio del logos y de la interacción entre ellos, además de que con el lenguaje se simbolizan muchos aspectos antropológicos, como menciona López Eire (2006):

[...] el lenguaje humano es retórico porque está, por un lado, fundamentalmente enfocado al «otro», al conciudadano, y por otro, porque se vale de unos signos, los símbolos, que no se relacionan con sus referentes más que por un acuerdo político-social (p. 24).

\section{Elocuencia frente a retórica}

Muchos estudiosos de la literatura griega han reconocido grandes valores de elocuencia en las obras homéricas; incluso Aristóteles considera a Homero el primer retórico de los griegos. Con respecto a esto, Pernot (2005) dice lo siguiente:

From the time of the Homeric poems, which are the first literary Greek texts, the spoken word and persuasion occupy an important place. I. J. F. de Jong has calculated that in the Iliad, speeches in direct discourse, by number of verses, represent 45 percent of the entire length of the poem. The epic, therefore, 
joins narrative and speech in an almost equal partnership by having the characters whose adventures it relates speak in a direct manner. Even in the midst of battles and dangers, the "winged words," as a formulaic expression calls them, constitute an essential dimension of Homeric poetry (p. 1) 1 .

Y es que hay un manejo poético que se refleja en el estilo elegante, sobrio y encantador de las palabras y de los giros expresivos que conforman las figuras literarias. De esta manera, se logra un estado del texto literario que dista mucho de los elementos representativos de los valores retóricos transmitidos por la tradición de los grandes teóricos de la antigüedad.

Como menciona Vernant (2003) acerca del mito, en el relato homérico podría configurarse un discurso formulado, de modo que las expresiones discursivas del cíclope en el diálogo con Odiseo pertenecen al entorno del conversar, del diálogo cotidiano en una interfaz comunicativa o, muy simplemente, de la labor poética y artística que imprime el poeta; mientras que Odiseo, su contrapartida, representa al individuo socialmente adaptado a una sociedad dialógica y congruente en sus intenciones discursivas.

Pero no hay que extrañarse por estas cosas. El lenguaje es por naturaleza de índole retórica, como lo manifiesta López Eire (2005), y lo poético, con una función expresiva en su elocución, llega a cierto grado de encantamiento retórico; sin embargo, hay un aspecto que engrandece el discurso retórico, la retoricidad del lenguaje que, como afirma López Eire (2006), es común a todo momento de discurso y por lo tanto conlleva todos los ingredientes necesarios para poner a prueba el intelecto humano. Pernot (2005) dice al respecto:

In the Iliad as in the Odyssey, the characters both human and divine begin to speak in all sorts of situations induced by the plot, and their speeches reflect all the imaginable forms of verbal exchange: monologue and dialogue, question and answer, narrative, enumeration and catalogue, order, promise, challenge, insult, rodomontade, prediction, consolation, transaction, and so forth. Often the desire to sway the person addressed is clear and pronounced, as in prayer scenes and scenes of request and supplication (p. 2) ${ }^{2}$.

Menciona Aristóteles (2001) que son muchos los lineamientos que deben seguirse para el perfecto uso y comprensión del discurso. Comienza por indicar que en retórica: prevalecen lo verdadero y lo justo por sobre sus contrarios; es necesario argumentar más que convencer y, si se trata de convencer, debe hacerse sobre los contrarios y con razonamiento, por ejemplo, se convence cuando se manifiesta una verdad; se debe exhortar y disuadir, elogiar y censurar, acusar y defender; deben aflorar sentimientos de compasión, dolor, piedad, generosidad y bondad; etcétera.

1 Ya desde la época de los textos homéricos, primeros textos literarios griegos, la palabra hablada y la persuasión ocupan un lugar importante. I. J. F. de Jong ha calculado que en la Ilíada los discursos directos, por cierto número de versos, representan el 45 por ciento de la totalidad del poema. La épica, en cuanto unifica la narración y el discurso (directo) en casi igual cantidad, tiene como característica principal unas aventuras que se relatan en el discurso directo. Incluso en medio de las batallas y peligros, las palabras libres, como fórmula de expresión, constituyen la esencia de la poesía homérica en toda su dimensión (traducción propia).

2 Tanto en la Ilíada como en la Odisea, los personajes, humanos y divinos, se expresan en todo tipo de situaciones inducidos por la trama, y sus discursos reflejan todo tipo de formas posibles en el intercambio verbal: monólogos y diálogos, preguntas y respuestas, narraciones, enumeraciones y listados, mandatos, promesas, retos, ofensas, jactancias, profecías, consuelos, tratados, y demás. A menudo, el deseo de influir sobre una persona determinada resulta claro y convincente, como en los ruegos y en las súplicas (traducción propia). 
Como puede observarse, aunque se actúe y se hable con pasión en el discurso poético y elocuente, es importante hacer prevalecer la razón. Polifemo no da un trato cordial a los visitantes; se muestra adverso a la situación de invasión por parte de los extranjeros; demuestra impiedad hacia ellos y hacia los dioses; demuestra también su condición de salvajismo cuando dice que va a devorar a los visitantes, señal indudable de la barbarie de un grupo social lejos de las condiciones idóneas para la convivencia acorde con las leyes.

Para entender mejor lo dicho hasta el momento, hay que poner ante nuestros ojos la famosa artimaña de Odiseo sobre Polifemo. Odiseo, después de penetrar en la caverna del cíclope y de quedar luego como prisionero de este, urde varios mecanismos de defensa para lograr su supervivencia. Da de beber al cíclope un excelente vino, lo embriaga y luego lo ciega. Finalmente, logra salir de la caverna gracias a su astucia, amarrándose al vientre de los carneros que estaban dentro de ella y que debían salir a pacer a la mañana siguiente. Pero la mejor de las tretas, por su astucia y sensatez, fue la de decirle su nombre de una manera velada, de modo que el engaño surtiera buen efecto.

El nombre que utiliza Odiseo en ese momento oportuno, el kairós griego, es el de oútis, 'nadie'. Solo la astucia de un ser políticamente desarrollado y con sus virtudes de nobleza y alto grado de educación podía confrontar la insensatez y el salvajismo de unos seres insociables, sin leyes y sin cultivos.

El kairós juega un papel muy importante, ya que modela los instantes precisos para adecuar el discurso al momento propicio, tal como se reconoce a nivel técnico este concepto:

A fundamental notion in ancient Greece, kairos carried a number of meanings in classical rhetorical theory and history, including "symmetry, "propriety," "occasion," "due measure," "fitness," "tact," "decorum", "convenience," "proportion," "fruit," "profit," and "wise moderation," to mention some of the more common uses. (Sipiora y Baumlim, 2002, p. 2) ${ }^{3}$.

Este rasgo de astucia demuestra que Odiseo era superior a Polifemo en lo que atañe a su condición de nobleza, de areté homérica, propia de los individuos que llevaban una vida de privilegios en la sociedad. Uno de estos privilegios era la condición educadora de la nobleza, el derecho de ser educado con valores de virtud y excelencia. Según Aristóteles (2001), es del hombre noble participar de la política y, por lo tanto, sobresalir en retórica.

Por otra parte, se evidencia la necesidad de cumplir con ciertos preceptos de la convivencia humana, y que son de orden divino: Odiseo manifiesta su deseo de llegar a su patria y que solo necesita unos víveres para su travesía, pero el cíclope se opone a ello y deja de cumplir con el don de la hospitalidad, también irrumpe contra los compañeros de Odiseo, a quienes destroza y los devora. Aquí no se cumplen las acciones recíprocas que se ejercen entre los ciudadanos que forman una comunidad política:

Los seres humanos poseen en el lenguaje un sistema de comunicación que los caracteriza frente a otras especies animales, dotado de mil ventajas y servicios, como la intercambiabilidad, la posibilidad de diálogo y diversificación, la capacidad mimética y simbólica, las múltiples opciones de diversificación contextual, la posibilidad de combinar el lenguaje con otros sistemas de signos y símbolos, el carácter ilimitado de los mensajes, etc. (López Eire, 2006, p. 27).

3 Un concepto fundamental en la antigua Grecia, kairós, tenía una serie de significados en los tratados de retórica clásica y en la historia, entre ellos 'proporción', 'autoridad', 'momento oportuno', 'conveniencia', 'aptitud', 'decoro', 'sentido', 'pertenencias', ‘descendencia' y 'sabia moderación', solo por mencionar algunos de los usos más comunes (traducción propia). 
Hablando retóricamente, resulta irónico el nombre mismo de Polifemo ${ }^{4}$, elocuente, pero ya se indicó que su habla obedece a momentos de dominio poético. $\mathrm{O}$ acaso ¿es a partir de esta interpretación del nombre como lo mucho que se dice (de él) que poetas como Ovidio, Teócrito y Góngora dedicaron sus líneas poéticas sobre el amor y las cuitas de Polifemo con Galatea?

\section{Mito y política}

Los mitos son parte esencial de la vida e idiosincrasia de muchos pueblos y culturas que se han valido de ellos como forma de explicar su entorno natural. Por tanto, los mitos forman un conglomerado cultural asociado también a la política, y afectan las verdades más esenciales, tal y como afirma Vernant (2003):

[...] rasgo común es el de ser relatos capaces de seducir al auditorio, que debe sentir al escucharlos el mismo placer que obtiene de los cuentos y las fábulas, pero a la vez ser relatos serios que, bajo la forma de lo ficticio y de lo fantástico, hablan de cosas completamente esenciales, que afectan a las verdades más profundas de la existencia (p. 184).

También indica Vernant (2003) que el mito es una enseñanza y un modelo de vida ${ }^{5}$. El mito no vale a veces por sí mismo, sino, como dice Vernant (2003), "por su relación con otra cosa, como ejemplo de la acción o de la conducta propuesta para la imitación de los hombres" (p. 178).

Con la instauración de la polis en los estados griegos se constituyó una forma de convivencia de los ciudadanos. Aristóteles (1989) manifiesta que de la polis, como instrumento de valorización de los asuntos de ese estado por medio de las leyes, los magistrados y una conciencia plena de los juicios de cada individuo, surge todo un espectro de relaciones interpersonales y comunitarias que derivan en la caracterización de los ciudadanos, es decir, en la estratificación social de ellos. Así, se caracterizan los nobles y aristócratas frente a los libertos, esclavos y extranjeros.

For Aristotle, for example, ta politika did not mean 'politics' in any universally applicable sense, but specifically matters concerning the polis; and the polis as he construed it was a natural organism within which alone could generic man attain his intrinsic natural end of living the good life (Cartledge, 2009, p. 14) ${ }^{6}$.

La política es, por lo tanto, la perfecta comunión de los individuos con sus virtudes y atributos en la sociedad, como lo da a entender Ezquerra Gómez (2009). A la vez, la política7 constituye una unidad dentro de un entramado de condiciones sociales en la que deben lograrse las mejores relaciones comunes:

Greek political theory was not by any means solely about power, however, and politeia, the Greek word that we translate as 'constitution', both was used (and maybe coined) to denote citizenship and had a wider frame of reference than either our 'constitution' or 'citizenship'. This reflected the fact that the polis was imagined as a moral community of active participatory citizens, not as a mere political abstraction (Cartledge, 2009, p. 21) .

$4 \quad$ Polifemo, el que se expresa de múltiples maneras.

$5 \quad$ Aunque es una explicación de otro mito, se puede aplicar a otros mitos.

6 Para Aristóteles ta Politika no significaba política en un sentido universal moderno, sino específicamente asuntos relacionados con la polis y la polis que él concibió fue un organismo natural en el que los humanos solo podían atenerse al fin natural e intrínseco de vivir una excelente vida (traducción y subrayado propios).

7 En su artículo, Ezquerra Gómez relaciona etimológicamente el vocablo polis con otros vocablos griegos que designan la idea de pletórico y de multitud, como pleos 'lleno', polýs 'mucho' y plethos 'multitud'.

8 En la teoría política griega no solo se teoriza acerca del poder (político), sino que además politeia, palabra griega traducida como derecho (estatal), se usó (y se acuñó) para denotar la ciudadanía (participativa) y 
También se puede ver que el relato homérico es simbólico e indicador de ciertos rasgos antropológicos que contraponen dos culturas:

\begin{abstract}
Los griegos no conciben el poder como fuerza nuda, caprichosa, irracional. El significado y el sentido del poder se transluce en su relato mítico.

El simbolismo del mito parecería indicar que del ejercicio de un poder andamiado por la prudencia cabe esperar la sabiduría, condición necesaria para enunciar la ley organizadora que posibilita la vida en comunidad. Vida en común, a partir de la creación del vínculo que implica alianza y obligación para el logro de la tarea propuesta. Vínculo nacido de la necesidad y corporizado en la norma que vehiculiza la concepción de la justicia. La ley incluye, fraterniza, protege a los que la admiten y la cumplen. Y es en la norma vivenciada como justa donde anida la esperanza de convivir con los "hijos" de Zeus: amor, paz, armonía, belleza, alegría. La ley también excluye, sanciona al transgresor. Prometeo es testigo de ello: su desobediencia lo encadena a una roca (Nosei, 2015, p. 210).
\end{abstract}

El mito del cíclope contiene algunos elementos de orden natural que pueden sugerir la idea de lo apolítico. Los cíclopes viven en grutas, no cultivan los campos (oúte fyteuousin, out'aroosin), solo recogen los frutos que nacen por sí solos, no tienen leyes ni vida social (oúte themistes), solo se ayudan mutuamente en circunstancias especiales, como cuando acuden los demás al llamado de Polifemo en la huída de Odiseo; simplemente ordeñan cabras y comen la carne cruda. Estos son indicios de una vida agreste, silvestre y salvaje, enmarcada lejos de un estado bucólico ${ }^{9}$ en concordancia con las condiciones sociales aceptables.

También este mito contiene indicios del contraste humano que representan Odiseo y Polifemo. Cuando Odiseo se va acercando a la isla de los cíclopes, embarca en una isla que se ubica al frente de la de estos. Simbólicamente, esto sería una representación de una sociedad intermedia, a medio camino de la sociedad que ha alcanzado una supremacía política y en la que los ciudadanos conviven con algún grado de cohesión social y de oportunidades privilegiadas, representada por Odiseo. Morábito (1987) afirma:

Los cíclopes, puesto que no pueden alcanzarla (pues ella representaría sin duda la primera etapa de cualquiera de sus travesías), muestran su incapacidad de expandirse en el mundo. ¿Qué es en efecto esa isleta sino el natural trampolín desde el cual el mundo podría tornarse accesible y familiar, la plataforma que les permitiría salir y volverse verdaderamente adultos, capaces de enfrentarse a la escasez exterior? (p. 87).

Por el contrario, los cíclopes conservan sus rasgos rurales sin progreso y sin avances tecnológicos, ni siquiera han logrado avances en navegación, ya que no han logrado cruzar hasta la isla que tienen al frente. Quizá el hecho de la llegada de Odiseo sea un indicador de que deben darse cambios profundos y necesarios en las sociedades.

El estado ciclópeo es arcaico y muy lejos de lo moderno. De hecho, a Odiseo, socializado políticamente, Homero le da los atributos de polimetes y de politropos, mientras que de los cíclopes dice que son athemistoi (sin justicia, sin leyes). ¿Acaso no equivale este atributo de los cíclopes a ese estado prehistórico? El término contrario themistoi ${ }^{10}$ hace referencia al orden establecido socialmente en distintos ámbitos de la cultura: se pone orden en la legislación de un pueblo; se establecen disposiciones culturales, artísticas y tecnológicas; también se dan los fundamentos militares y se asientan las prorrogativas económicas. De los

tuvo una más amplia referencia que las modernas constitución y ciudadanía. Esto evidencia el hecho de que la polis fue entendida como una comunidad de costumbres de los ciudadanos cívicamente activos, no como una mera abstracción política (traducción y subrayado propios).

9 Se pretende contrastar lo bucólico verdadero de las sociedades en convivencia social con lo salvaje y agreste de otras sociedades apolíticas.

10 the es la misma raíz de Themis, títhemi, etcétera. 
cíclopes, Homero menciona que cada uno tiene su propia ley (themisteúei de hékastos). En fin, tenemos todo un conjunto de situaciones que enmarcan la vida social y política de los hombres que han aprendido a convivir mutuamente. Los cíclopes estarían condenados a ese estado de aislamiento antropológico.

Con esto, también hay que revalorizar el concepto de símbolo y ver en él parte del dominio del lenguaje. López Eire (2006) dice al respecto:

El empleo de símbolos es una forma convencional, arbitraria (sólo muy moderadamente icónica) y aprendida a partir
de la acción político-social, lo que significa necesariamente que el hombre es verdaderamente un animal político-
social y simbólico, y que, a partir de su dominio del lenguaje, da sentido a muchas actividades específicamente
humanas que se distinguen netamente de las actividades del animal (p. 25).

Si se observan los rasgos físicos de los cíclopes, el hecho de tener un único ojo en su frente podría ser indicio de que, intelectualmente, están muy limitados en la capacidad de interactuar socialmente y de converger hacia estados de desarrollo muy particulares y exitosos, tal como se nos presenta en nuestra sociedad común con su organización y perfeccionamiento civil.

\section{La antítesis Polifemo-Odiseo}

Una de las características de la argumentación en retórica es el uso de figuras de pensamiento, como el entimema ${ }^{11}$, la antítesis ${ }^{12}$, las sentencias, etcétera. En el relato acerca del cíclope abunda una serie de contrarios que manifiestan una categorización de orden político.

Como ya se ha dicho, Odiseo representa o simboliza el hombre político que ha alcanzado el nivel social con las condiciones sociales apropiadas para su organización y desempeño civil; incluso con refinamiento y grandeza cultural, mientras que el cíclope Polifemo solo alcanza el carácter agreste de las costumbres. De esto se logra un modelo de contrarios o antítesis entre estos personales, los cuales se describen a continuación.

Desde el punto de vista del mito, Odiseo es el héroe que se aventura a grandes hazañas personales y humanas, mientras Polifemo es el antihéroe que solo atina a convivir con sus rebaños. Polifemo se caracteriza por su monstruosidad. Es el gigante de un único ojo con el que mira únicamente hacia sus deseos de supervivencia, ya que vive solo para subsistir. Se puede reafirmar esto con palabras de Morábito (1987):

El ojo único de Polifemo se relaciona así con una época de abundancia anterior a la agricultura, a las leyes y a la
religión. Como afirman Adorno y Horkheimer, el ojo único constituye un signo mismo de la prehistoria, puesto
que recuerda la nariz y la boca, más primitivos que la simetría de los ojos, y esa simetría es lo único que llega a
proporcionarnos, a través de la unidad de dos percepciones convergentes, las experiencias de la identificación, de la
profundidad y la objetividad (p. 86).

Prototípicamente, Odiseo es uno de esos personajes atléticos y esbeltos, propio de la cultura civilizada, de la areté aristocrática homérica. El cíclope, por su parte, se dedica al pastoreo y solo ve el carácter agreste en su vida. No falta decir que Homero caracteriza a los cíclopes por su soberbia (hybristai). También siente el desdeño de los dioses, excepto el de Poseidón, el padre; mientras Odiseo contempla el apoyo y ciertos cuidados de Atenea. La caverna contrasta con la pólis, lo que sugiere que unos viven en el salvajismo, al contrario de otros que viven en un rango de civilización con derechos y leyes que protegen sus actos y su

11 Figura de pensamiento cuya construcción omite parte de la expresión, pero no el contenido.

12 Figura de pensamiento que contrapone una idea a otra. 
patrimonio. Con esto, se entiende que en una sociedad civilizada y política los individuos toman sus decisiones y sus deliberaciones en la asamblea, en el ágora o en lugares públicos (out'agorai bouleforoi), para dictaminar sus leyes, sus derechos y su justicia (oúte themistai). Otra situación que pone en desventaja a los cíclopes es la carencia de las costumbres industriales, ya que no se dedican a la navegación, ni mucho menos al comercio entre factorías.

También se contraponen aspectos primordiales del ser humano como el hecho del raciocinio en diversas situaciones de la vida. Odiseo es el ser astuto, ayudado por la metis, precavido, sensato y con grandes dotes de razonamiento. Todo lo contrario es Polifemo, quien participa de la inconsciencia hasta el punto de olvidar un vaticinio en el que se le predecía que iba a ser cegado por Odiseo. Además, Odiseo es el hombre sumamente ingenioso, politropos, que pasa constantes peligros, se escabulle de la muerte $\mathrm{y}$, como héroe, adquiere fama y reconocimiento, mientras que los cíclopes solo tienen una visión unívoca y frontal del mundo, y ni siquiera respetan las leyes de hospitalidad común a los hombres, como afirma Morábito (1987):

¿Qué valor pueden tener estas reglas para quienes viven en un eterno presente sin expectativas, cuyo ojo central y telescópico los obliga a una visión unívoca y frontal del mundo, sin reveses ni futuro, fiel en todo y por todo a la naturaleza benigna y petrificada en la que viven? (p. 88).

Al final del canto nueve de la Odisea, el cíclope cae en cólera al descubrir la verdad del forastero, Odiseo, quien se da a conocer con su nombre verdadero y el cíclope cae en cuenta del vaticinio. Es el momento de cólera de Polifemo e, irónicamente, es Odiseo el que se mantiene ecuánime y tranquilo y se proclama vencedor, ya que su nombre podría estar relacionado con un verbo griego que significa irritarse, encolerizarse ${ }^{13}$, tal como lo indica Bernabé (1992). Por su parte, Polifemo queda muy mal ante los demás cíclopes cuando estos le dicen que si nadie le profirió tal desgracia, entonces, como castigo de Zeus tiene su merecido. Los otros cíclopes sí son más razonables en el uso del lenguaje, ya que usan un recurso dialéctico, un silogismo.

\section{Conclusiones}

El mito del cíclope Polifemo indica que él es un ser apolítico y, por lo tanto, se concluye que es un ser irracional. Y esto es así por varios motivos. En primer lugar, no hace uso del discurso dialógico-dialéctico, sino apenas comunicativo; es decir, no usa el lenguaje dialéctico propio del de los recursos retóricos, como lo son: servirse de una buena argumentación, hacer que prevalezca lo justo y lo verdadero, poner a prueba y sostener un aserto, tratar de convencer a su interlocutor o poseer un atinado razonamiento. En segundo lugar, tal es su incapacidad para el lenguaje lógico que desconoce cómo dar forma a analogías y a aducciones y cómo crear ambigüedades y dobles sentidos. Además, el hecho de no pertenecer a una gloriosa familia lo limita y le impide tener como representación social las asambleas y también le impide gozar de una vida civil adecuada para la retoricidad del ser político griego.

Su irracionalidad se simboliza, también, en elementos como su vida silvestre, la falta del carácter industrial, su monstruosidad, su insensatez y su impiedad. A la vez, representa una amenaza para el ser político, como manifiesta López Saco (2013):

13 El verbo es odyssomai bajo la forma odysat (Odisea, 5, v. 340). 
El hombre salvaje, a diferencia del bárbaro, que era una amenaza para la sociedad en su conjunto y para los resortes de la cultura y la civilización, representaba una seria amenaza al individuo. Bien como destino ineludible bien como némesis, el salvaje, el ente agreste y monstruoso, era una condición en la que el individuo podía degenerar, en especial si estaba alejado de la ciudad o al margen de los centros organizados de cultura (p. 5).

Su insensatez lo pone en desventaja ya que solo se sirve de la fuerza bruta, y no de lo intelectual y su único ojo lo representa como un ser irracional. Carece de toda retoricidad.

\section{Bibliografía}

Aristóteles. (1989). La política. (M. Briceño Jáuregui, trad.). Bogotá: Publicaciones del Instituto Caro y Quintero.

Aristóteles. (2001). Retórica. (A. Bernabé, trad.). Madrid: Alianza Editorial.

Bernabé, A. (1992). Una forma embrionaria de reflexión sobre el lenguaje: la etimología de nombres divinos en los órficos. Revista española de lingüística, 22(1), 25-54.

Cartledge, P. (2009). Ancient Greek Political Thought in Practice. Cambridge: Cambridge University Press.

Choza, J. y P. Choza. (1996). Ulises, un arquetipo de la existencia humana. Barcelona: Editorial Ariel.

Ezquerra Gómez, J. (2009). Pólis y Caos. El espacio de la político. Revista Res Publica, (21), 21-37.

López Eire, A. (2005). "La naturaleza retórica del lenguaje”. Revista de Retórica y Teoría de la Comunicación, 5(8-9), 5-249.

López Eire, A. (2006). En torno a la "retoricidad" del lenguaje. Revista Humanitas, 58, 23-43.

López Saco, J. (2013). Monstruosidad y salvajismo: trazas míticas en el marco de la racionalidad griega antigua. Presentia, 14, 1-21.

Morábito, F. (1987). El ojo de Polifemo. Acta Poética, 7(1-2), 85-94.

Nosei, A. C. (2015). La construcción del sujeto político: la narrativa cívica. Anuario de Facultad de Ciencias Humana, 6, 207-214.

Omero. (2009). Odissea. (R. Calzecchi Onesti, trad.). Torino: Giulio Einaudi editore.

Pernot, L. (2005). Rhetoric in Antiquity. Washington, D.C.: The Catholic University of American Press.

Sipiora, P. y Baumlim, J. (2002). Rhetoric and Kairos. N.Y: N.Y. University Press.

Vernant, J. P. (2003). Mito y sociedad en la Grecia antigua. Madrid: Siglo XXI. 
